Article

\title{
A Continuous Procedure Based on Column Chromatography to Purify Anthocyanins from Schisandra chinensis by a Macroporous Resin plus Gel Filtration Chromatography
}

\author{
Daran Yue ${ }^{1}$, Lei Yang ${ }^{2}$, Shouxin Liu ${ }^{1}$, Jian Li ${ }^{1}$, Wei $\mathrm{Li}^{1,3, *}$ and Chunhui Ma ${ }^{1, *}$ \\ 1 College of Material Science and Engineering, Northeast Forestry University, Harbin 150040, China; \\ yuedaran@163.com (D.Y.); liushouxin@126.com (S.L.); nefulijian@163.com (J.L.) \\ 2 Key Laboratory of Forest Plant Ecology, Ministry of Education, Northeast Forestry University, \\ Harbin 150040, China; ylmanefu@163.com \\ 3 Key Laboratory of Wood Science and Technology of Zhejiang Province, Zhejiang Agriculture and \\ Forestry University, Hangzhou, Lin'an 311300, China \\ * Correspondence: liwei19820927@126.com (W.L.); mchmchmchmch@163.com (C.M.); \\ Tel.: +86-451-8219-1204 (W.L.)
}

Academic Editor: Derek J. McPhee

Received: 2 December 2015; Accepted: 3 February 2016; Published: 6 February 2016

\begin{abstract}
In our previous study, as natural food colorants and antioxidants, the color and content stabilities of Schisandra chinensis (S. chinensis) anthocyanins were investigated. In this work, the purification process parameters of $S$. chinensis anthocyanins using a macroporous resin and gel filtration chromatography were evaluated. The optimized parameters of static adsorption and desorption were as follows. The selected resin is HPD-300 (nonpolar copolymer styrene type resin), and the anthocyanins adsorption saturation capacity of HPD-300 resin was $0.475 \mathrm{mg} / \mathrm{g}$ dry resin. Adsorption time was $4 \mathrm{~h}$, and $0.517 \mathrm{mg} / \mathrm{mL}$ of $S$. chinensis anthocyanins was adsorbed on the resin column with a flow rate of $39 \mathrm{~mL} / \mathrm{h}(3 \mathrm{BV} / \mathrm{h})$. After adsorption, the anthocyanins were completely desorpted with $2.5 \mathrm{BV}$ of $90 \%(v / v)$ ethanol solution, and the desorption flow rate was $13 \mathrm{~mL} / \mathrm{h}(1 \mathrm{BV} / \mathrm{h})$. After purification by dynamic adsorption and desorption, the anthocyanins content in the effluent increased from $47.6 \mathrm{mg} / \mathrm{g}$ to $128.4 \mathrm{mg} / \mathrm{g}$, the purity of anthocyanins increased six-fold from $5.08 \%$ to $30.43 \%$, and the anthocyanins recovery was $96.5 \%$. The major constituent of S. chinensis anthocyanins was isolated with Bio-Gel P2 gel filtration chromatography, and it was detected by liquid chromatography electrospray ionisation tandem mass spectrometry (LC-ESI-MS) as cyanidin-3-O-xylosylrutinoside. Moreover, the antioxidant activities of S. chinensis anthocyanins were investigated. After purification using the HPD-300 resin, the antioxidant activities of anthocyanins were increased 1.2-fold (FRAP) and 1.7-fold (ABTS).
\end{abstract}

Keywords: Schisandra chinensis; anthocyanins; macroporous resin; gel filtration chromatography; LC-ESI-MS; antioxidant activities

\section{Introduction}

Anthocyanins, an important source of natural colorants, have recently been applied in cosmetics, food, and pharmaceuticals because of the present trend towards replacing synthetic colorants [1]. Chemically, anthocyanins are glycosides of polyhydroxy and polymethoxy derivatives of 2-phenylbenzopyrylium or flavylium salts [2]. Anthocyanins as a group of flavonoid phenolic compounds are soluble in polar solvents such as acidified methanol, ethanol and water. Anthocyanins have numerous health beneficial properties, such as the prevention of heart disease, inhibition of 
carcinogenesis [3,4], anti-inflammatory activity [5], and antioxidant [6] and free-radical scavenging activities [7]. Therefore, there is an increased interest in the use of anthocyanins in functional food, nutraceutical and pharmaceutical industries.

Schisandra chinensis (Turcz.) Baill. (S. chinensis) fruits, used as a traditional medicinal herb and food additive, are widely distributed and cultivated in China, the Russian Far East, Korea and Japan [8]. Extensive studies have indicated that the major bioactive components of $S$. chinensis fruit are essential oils [9,10], biphenyl cyclooctene lignans [11-13], and anthocyanins [14].

Despite anthocyanins being found in many plant species, including strawberries [15], blueberries [16], blackberries [17] blackcurrants [15], black carrot [18], mulberries [19], red grapes [20], purple potatoes [21], red raspberries [22] and so on, there are almost no studies on purified S. chinensis anthocyanins using a macroporous resin. Moreover, compared to the conventional method, the macroporous resin enrichment is more effective because of its high efficiency, reduced solvent consumption, low cost, harmlessness to the environment, etc.

Recently, single separation technology has been unable to meet the high efficient production level. Therefore, the combination of chromatography technology received extensive attention of the researchers. The combined method of macroporous resin plus gel filtration chromatography in our study is investigated for purification of $S$. chinensis anthocyanins.

Therefore, in this work, the process parameters of purifying anthocyanins using a macroporous resin were investigated, and the main constituent of $S$. chinensis anthocyanins, which was isolated using Bio-Gel P2 gel filtration chromatography, was analyzed using liquid chromatography electrospray ionisation tandem mass spectrometry (LC-ESI-MS). Moreover, the antioxidant activities, including the total phenolic content, ferric reducing antioxidant power and free radical scavenging activity of S. chinensis anthocyanins (before and after purification with macroporous resin) were studied.

\section{Results and Discussion}

\subsection{Static Adsorption and Desorption Tests of Anthocyanins}

\subsubsection{Screening of Macroporous Resins}

The appropriate macroporous resin was selected based on the capacity of adsorption and desorption, the ratio of desorption, and the adsorption speed. The adsorption capacity and the desorption capacity of all the resins tested in this study are shown in Table 1. Anthocyanins are polar compounds, which meant the polar resin had the highest adsorption ratio and a higher desorption ratio for anthocyanins. Among the tested resins, the nonpolar copolymer styrene type resin HPD-300 and HPD-5000 resins had the higher adsorption ratios (94.0\% $\pm 0.6 \%$ for HPD-300 and $84.9 \% \pm 0.6 \%$ for HPD-5000) and the HPD-200L and HPD-5000 had the higher desorption ratios $(87.2 \% \pm 0.7 \%$ for HPD-200L and $84.6 \% \pm 0.6 \%$ for HPD-5000) for anthocyanins. This indicated that a bigger average pore diameter of resin aided desorption. However, the selectivity of a single solute in multi-solute system decreased because of the increase in average pore diameter, which resulted in a high desorption ratio but low adsorption and desorption capacities [23]. In order to comprehensively evaluate the adsorption ratio and desorption ratio, HPD-300, HPD-5000 and HPD-200L were used for the adsorption and desorption kinetics tests.

\subsubsection{Adsorption and Desorption Kinetics Curves}

The adsorption and desorption kinetics curves for anthocyanins on HPD-300, HPD-5000 and HPD-200L are shown in Figure 1. The adsorption capacity of anthocyanins increased with adsorption time and tended to equilibrate at about $5 \mathrm{~h}$ (Figure 1a). In the first $3 \mathrm{~h}$, the adsorption capacity increased slowly, and between 3 and $5 \mathrm{~h}$ it increased rapidly, while after $5 \mathrm{~h}$ the slope of curve indicated equilibrium was reached. The desorption ratio of anthocyanins increased with desorption time, and reached equilibrium at about $4 \mathrm{~h}$ (Figure 1b). A comprehensive evaluation of the 
adsorption-desorption ratio and kinetics curves for anthocyanins indicated that HPD-300 was the best resin for purifying the $S$. chinensis anthocyanins.

Table 1. Physical properties and static adsorption-desorption characteristics of the test macroporous resins.

\begin{tabular}{|c|c|c|c|c|c|c|}
\hline $\begin{array}{l}\text { Trade } \\
\text { Name }\end{array}$ & Polarity $^{a}$ & $\begin{array}{c}\text { Surface Area } \\
\left(\mathrm{m}^{2} / \mathrm{g}\right)\end{array}$ & $\begin{array}{c}\text { Average Pore } \\
\text { Diameter }^{\text {a }}(\mathrm{nm})\end{array}$ & $\begin{array}{c}\text { Moisture } \\
\text { Contents (\%) }\end{array}$ & $\begin{array}{c}D_{e} \text { of Anthocyan } \\
\text { in }^{b}(\%)\end{array}$ & $\begin{array}{c}D_{d} \text { of Anthocyan } \\
\text { in }^{b}(\%)\end{array}$ \\
\hline HPD-100 & Non-polar & $650-700$ & $85-90$ & $65.00 \pm 1.85$ & $81.4 \pm 0.5$ & $70.8 \pm 0.5$ \\
\hline HPD-100A & Non-polar & $650-700$ & 95-100 & $66.67 \pm 1.01$ & $36.8 \pm 0.6$ & $67.4 \pm 0.6$ \\
\hline HPD-300 & Non-polar & $800-870$ & $80-85$ & $75.52 \pm 1.77$ & $94.0 \pm 0.6$ & $79.9 \pm 1.2$ \\
\hline HPD-700 & Non-polar & $650-700$ & 85-90 & $66.10 \pm 1.31$ & $59.4 \pm 0.2$ & $65.5 \pm 0.6$ \\
\hline HPD-5000 & Non-polar & $550-600$ & $100-110$ & $73.28 \pm 1.32$ & $84.9 \pm 0.6$ & $84.6 \pm 0.6$ \\
\hline AB-8 & Weak-polar & $480-520$ & $130-140$ & $65.00 \pm 1.24$ & $66.2 \pm 0.3$ & $81.9 \pm 0.8$ \\
\hline D101 & Weak-polar & $400-600$ & $100-120$ & $66.47 \pm 1.62$ & $77.4 \pm 0.9$ & $72.5 \pm 0.8$ \\
\hline HPD-400 & Polar & $500-550$ & $75-80$ & $68.93 \pm 1.73$ & $70.8 \pm 0.8$ & $80.6 \pm 1.1$ \\
\hline HPD-200L & Polar & $500-550$ & $80-90$ & $72.86 \pm 1.33$ & $77.8 \pm 1.1$ & $87.2 \pm 0.7$ \\
\hline HPD-400A & Polar & $500-550$ & $85-90$ & $66.48 \pm 1.64$ & $62.7 \pm 1.2$ & $72.8 \pm 0.5$ \\
\hline HPD-450 & Polar & $500-550$ & $90-110$ & $72.00 \pm 1.58$ & $53.6 \pm 2.0$ & $67.9 \pm 1.0$ \\
\hline HPD-750 & Polar & $650-700$ & $85-90$ & $57.58 \pm 1.87$ & $50.7 \pm 1.1$ & $63.4 \pm 0.9$ \\
\hline HPD-500 & Strong-polar & $500-550$ & $55-75$ & $70.45 \pm 1.77$ & $32.5 \pm 0.4$ & $62.5 \pm 1.7$ \\
\hline HPD-600 & Strong-polar & $550-600$ & $80-90$ & $69.32 \pm 1.75$ & $32.3 \pm 0.4$ & $62.9 \pm 0.4$ \\
\hline HPD-850 & Strong-polar & $1100-1300$ & $85-95$ & $46.81 \pm 1.44$ & $33.8 \pm 0.8$ & $87.4 \pm 0.6$ \\
\hline
\end{tabular}

a Parameters in the table provided by manufacturer of the resins. ${ }^{\mathrm{b}}$ In the static absorption and desorption experiment, $1.0 \mathrm{~g}$ adsorbent (dry resin weight) together with $50 \mathrm{~mL}$ of extract solution were added into a flask, shaken $(100 \mathrm{rpm})$ for $8 \mathrm{~h}$ at $25^{\circ} \mathrm{C}$. After adsorption, the resins were washed with $50 \mathrm{~mL}$ deionized water and then static desorption was also performed in the shaker at $25^{\circ} \mathrm{C}$ for $8 \mathrm{~h}$. The process was repeated three times.
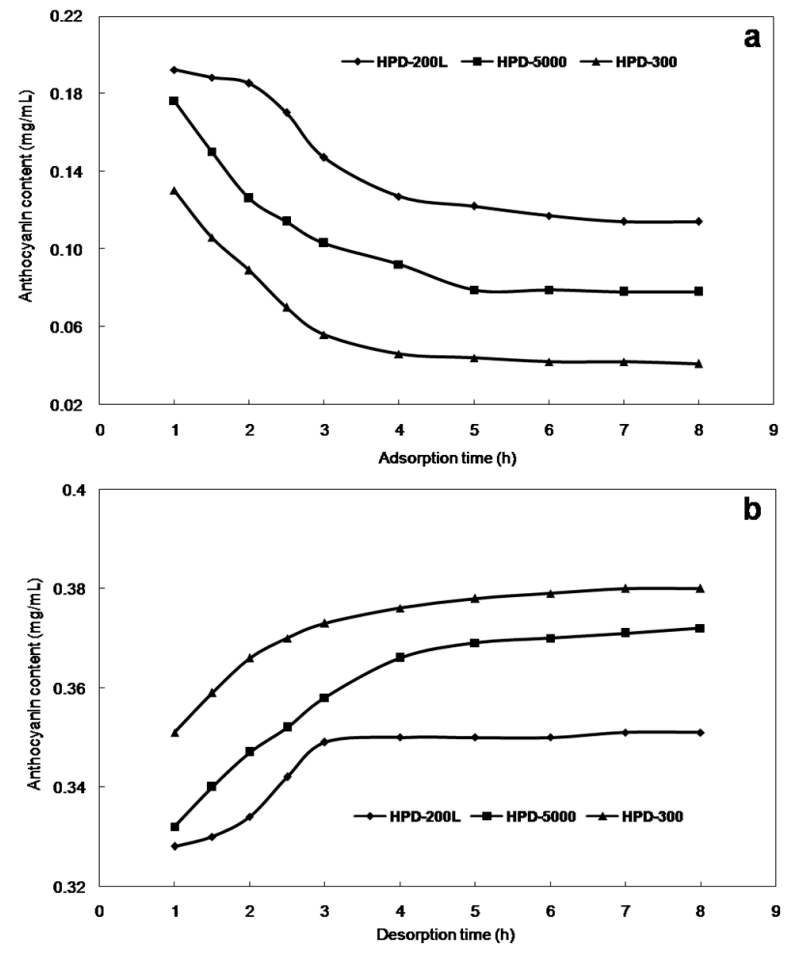

Figure 1. The adsorption (a) and desorption (b) kinetic curves for S. chinensis anthocyanins on HPD-300 resin.

\subsubsection{Adsorption Temperature}

Adsorption tests of anthocyanins on the HPD-300 resin were performed at four different temperatures (Figure 2). With the same initial concentration of anthocyanins, the adsorption capacities decreased as the temperature increased from 0 to $40{ }^{\circ} \mathrm{C}$, and the adsorption was slower than desorption, which implied that the adsorption process was exothermic. This indicated that the 
adsorption process should be carried out at lower temperatures. Therefore, $0{ }^{\circ} \mathrm{C}$ was selected as the adsorption temperature.

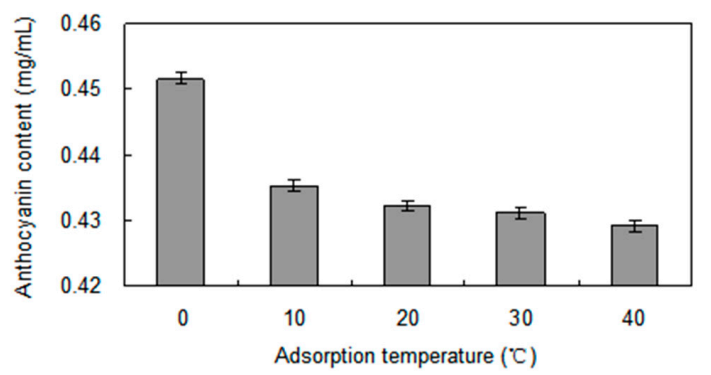

Figure 2. Effect of absorption temperature on S. chinensis anthocyanins content with HPD-300 resin.

\subsubsection{Adsorption Isotherms}

The parameters of adsorption isotherms were obtained for anthocyanins (Table 2) with an initial anthocyanins concentration of $0.474 \mathrm{mg} / \mathrm{mL}$.

Table 2. Parameters of adsorption isotherms.

\begin{tabular}{cccccccc}
\hline $\mathrm{T}^{\mathbf{a}}\left({ }^{\circ} \mathbf{C}\right)$ & $C_{i}{ }^{\mathbf{b}}(\mathbf{m g} / \mathbf{m L})$ & $C_{e}{ }^{\mathbf{b}}(\mathbf{m g} / \mathbf{m L})$ & $\mathbf{n s}^{\mathbf{c}}(\mathbf{m g} / \mathbf{m g})$ & $\mathbf{n s} / C_{e}(\mathbf{L} / \mathbf{g})$ & $\ln C_{e}$ & $\ln \mathbf{n s}$ & $\ln \mathbf{n s} / \mathbf{l n} C_{e}$ \\
\hline 0 & 0.119 & 0.005 & 0.0057 & 1.14 & -5.298 & -5.167 & 0.98 \\
0 & 0.237 & 0.014 & 0.01115 & 0.796 & -4.269 & -4.496 & 1.05 \\
0 & 0.474 & 0.033 & 0.02205 & 0.668 & -3.411 & -3.814 & 1.12 \\
0 & 0.948 & 0.077 & 0.04355 & 0.565 & -2.564 & -3.134 & 1.22 \\
0 & 1.896 & 0.211 & 0.08425 & 0.399 & -1.556 & -2.474 & 1.59 \\
\hline
\end{tabular}

${ }^{\mathrm{a}} \mathrm{T}$ is the operation temperature of static adsorption test. ${ }^{\mathrm{b}} C_{i}$ and $C_{e}$ are the initial and equilibrium concentrations of anthocyanin, respectively. ${ }^{c} \mathrm{~ns}$ is the apparent adsorption quantity.

The equations and Langmuir and Freundlich correlation coefficients are summarized in Figure 3. The Langmuir equation assumes uniform adsorption on the surface of the macroporous resin, and that there was no force between the adsorbent molecules. It only applies to mono molecule layer adsorption. However, the Freundlich equation was derived according to the uneven adsorption on the surface of the macroporous resin hypothesis, and has been combined with the Langmuir adsorption model. The correlation coefficients of the Langmuir and Freundlich equations at $0{ }^{\circ} \mathrm{C}$ were 0.9805 and 0.9983 , respectively. The Freundlich equation provided the best description of the anthocyanins adsorption behaviour on the HPD-300 resin. The results indicated that the adsorption process was not a mono molecule layer adsorption. By a linear equation $\lg \mathrm{ns}=\lg \mathrm{a}+1 / n \times \lg C i$, and $\mathrm{a}=0.27,1 / n=0.7333$. Therefore, the Freundlich equation was ns $=0.27 C i^{0.7333}$.
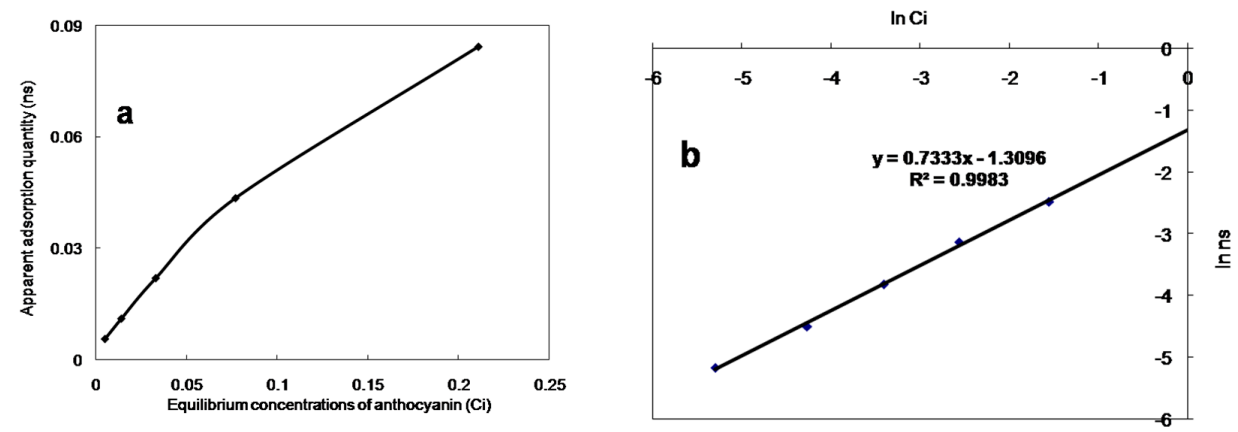

Figure 3. Langmuir adsorption isotherms (a) and Freundlich adsorption isotherms (b) of S. chinensis anthocyanins on HPD-300 resin. 


\subsection{Dynamic Adsorption and Desorption Tests of Anthocyanins}

\subsubsection{Dynamic Leakage Curves}

When the maximum quantity of solute has adsorbed on the resin, adsorption decreases or is balanced, and the solute desorbs from the resin. Consequently, it is important to construct leakage curves to evaluate the quantity of resin, the volume of sample solution, and the appropriate sample flow rate. The dynamic leakage curves obtained on HPD-300 resin were based on the volume of eluent and the flow rate. The results are shown in Figure $4 \mathrm{a}$ for the lower flow rate and the lower leakage $\left(C_{0}=0.47 \mathrm{mg} / \mathrm{mL}\right)$. At the lowest flow rate of $3 \mathrm{BV} / \mathrm{h}$, the best adsorption performance was obtained, which is likely because of better particle diffusion in the sample solutions. However, the lower flow rate increased the experimental time. Despite this, $3 \mathrm{BV} / \mathrm{h}$ was chosen as the most appropriate sample flow rate for further experiments. Under this condition, the leakage volume of sample solution was approximately 18 times the BV ( $234 \mathrm{~mL}$ ). In Figure $4 \mathrm{~b}$, the dynamic leakage curves shown for HPD-300 resin were based on the concentration of anthocyanins in the initial sample solution: the higher the concentration of anthocyanins, the faster the leakage. Therefore, the absorption action was easier at a lower concentration of absorbate solution. When the concentration of anthocyanins was $C_{0} / 4$, the leakage volume was approximately 20 times the BV $(260 \mathrm{~mL})$.
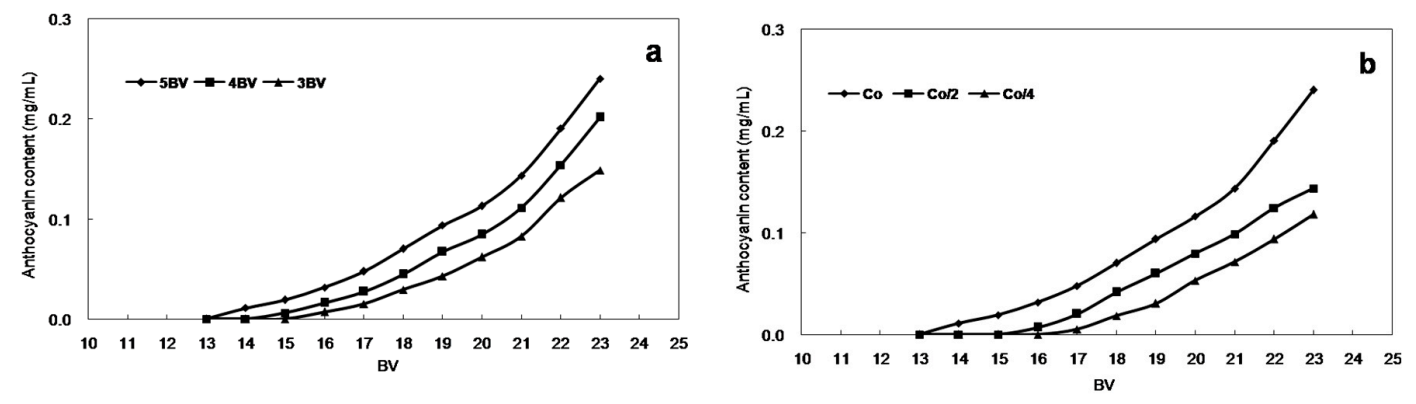

Figure 4. Leakage curves with (a) different current velocity and (b) different sample concentrations.

\subsubsection{Dynamic Desorption Curves}

Dynamic desorption curves on HPD-300 resin were obtained based on the volume and flow rate of the desorption solution. Ethanol-water solutions with different volume fractions $(30: 70,60: 40$, and 90:10, $v / v$ ) were used for the desorption tests. As the ethanol volume fraction increased, the desorption ratio increased rapidly (Figure 5a). To ensure the efficiency and economy of the process, ethanol-water $(90: 10, v / v)$ solution was selected as the desorption solution and used in the dynamic desorption experiment.
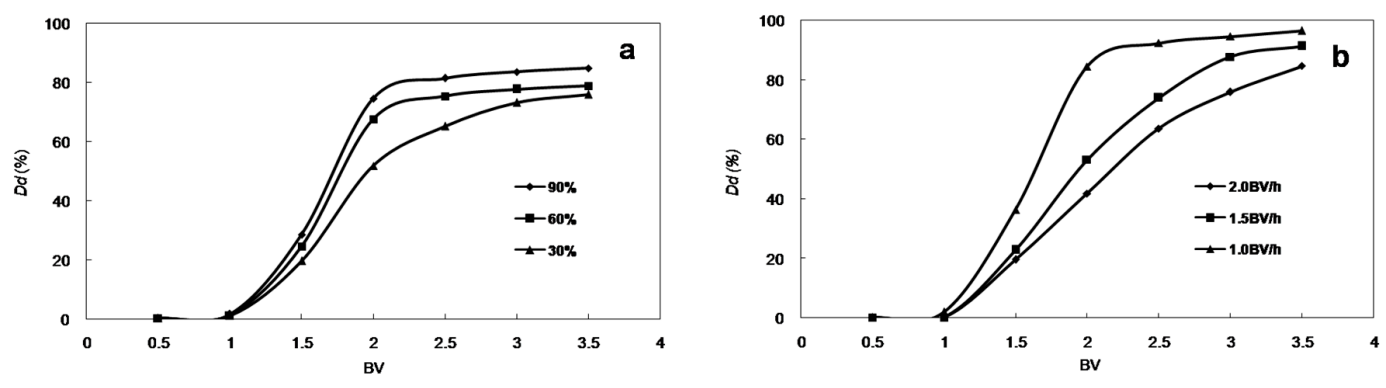

Figure 5. Dynamic desorption curves with (a) different ethanol volume fractions and (b) different current velocities (the ordinate is desorption ratio of anthocyanins).

The flow rates investigated in this test were $1,1.5$ and $2 \mathrm{BV} / \mathrm{h}$. At the flow rate of $1 \mathrm{BV} / \mathrm{h}$, anthocyanins were totally desorbed with a solvent volume of $2.5 \mathrm{BV}$ (Figure 5b). By comparison, 
at the flow rates of 1.5 and $2 \mathrm{BV} / \mathrm{h}$, anthocyanins were totally desorbed with a solvent volume of $3 \mathrm{BV}$. These results indicate that the lower desorption flow rate produced the most concentrated product among the flow rates tested. Therefore, this flow rate is better for the adsorption in terms of lower solvent use and high efficiency.

The dynamic adsorption and desorption results and optimized parameters can be summarized as follows. For adsorption, the concentration of anthocyanins in the sample solution was $0.474 \mathrm{mg} / \mathrm{mL}$. The processing volume was $260 \mathrm{~mL}(20 \mathrm{BV})$, and the flow rate was $3 \mathrm{BV} / \mathrm{h}$. It was then washed with $3 \mathrm{BV}$ deionized water at a flow rate of $3 \mathrm{BV} / \mathrm{h}$. For desorption, the elution solvent was $32.5 \mathrm{~mL}$ (2.5 BV) ethanol-water (90:10, $/ v)$ at a flow rate of $1 \mathrm{BV} / \mathrm{h}$. After purification using the HPD-300 resin, samples were combined, concentrated in a rotary evaporator, and dried under vacuum. The purity of anthocyanins increased six-fold from $5.08 \%$ to $30.43 \%$, and the anthocyanins recovery was $96.5 \%$. The dynamic desorption curves with different flow rates are shown in Figure 6.

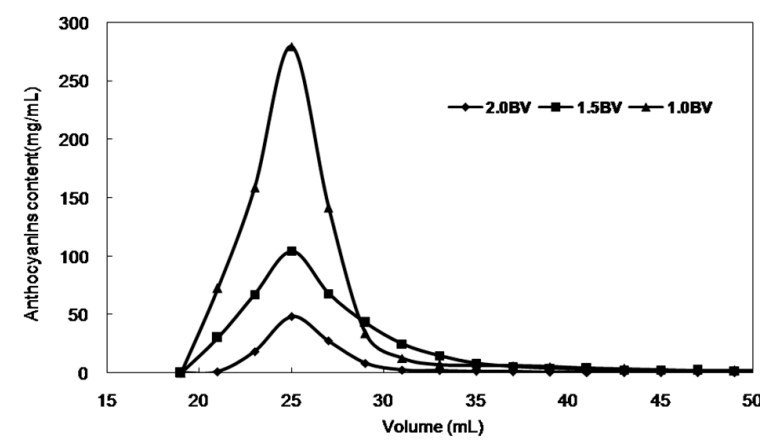

Figure 6. Dynamic desorption curves with different current velocities (the ordinate is the desorption content of anthocyanins).

\subsection{Gel Filtration Chromatography}

About $400 \mathrm{~mL}$ of anthocyanins solution, obtained by a scale-up experiment using macroporous resin was subjected to molecular exclusion chromatography, and a total of 100 fractions were collected (Figure 7). The gel-filtration resin used was Bio-Gel P2, and the recycle yield of anthocyanins (fractions 18-42) was $89.24 \%$. The results showed that the plus gel filtration chromatography is efficient for purification of anthocyanins from $S$. chinensis fruits as well as from other plant.

Figure 7 shows fractions that had ferric reducing antioxidant power (fractions 18-42). After the 45th fraction, non-ferric reducing antioxidant power was observed corresponding to non-targets polyphenols. Comparison with previous research results, on the content and color stability of S. chinensis anthocyanins [14] and the oxidation stabilities under different external conditions, were also investigated (The research results will be published in other article).

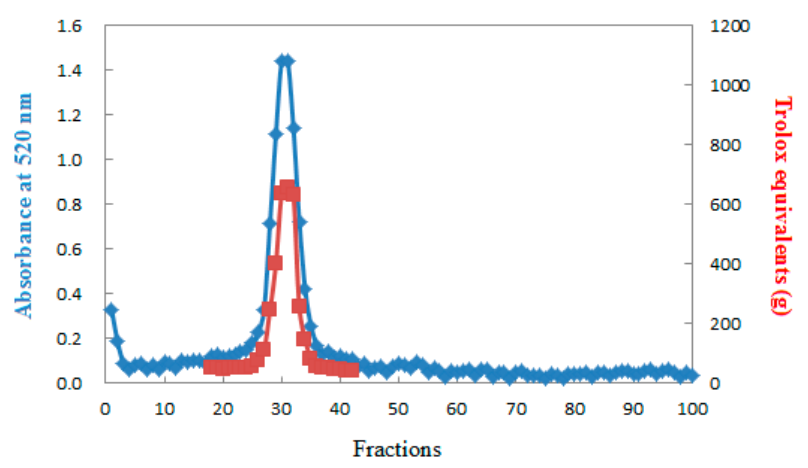

Figure 7. Gel filtration chromatography purification profile for S. chinensis anthocyanins after macroporous resin chromatography. 


\subsection{LC-MS Analysis of S. chinensis Major Anthocyanins}

The effluent liquid obtained from gel-filtration resin was concentrated under vacuum to dryness and then dissolved in 10\% methanol, and used for the structure determination of S. chinensis fruit anthocyanins by LC-ESI-MS (Figure 8).

A major Liquid chromatographic peak of S. chinensis anthocyan represented about $95 \%$ of the total absorbable compounds at $520 \mathrm{~nm}$, and the mass-to-charge ratio $(\mathrm{m} / \mathrm{z})$ and molecular weight of the major anthocyan was determined to be 727 [24]. As a result, it was confirmed that the relative intensity of the cyanidin-3-O-xylosylrutinoside (Cya-3-O-xylrut; $m / z$ 727) decreased with an increase in fragmentor voltage, whereas the $m / z 287.1$ assigned to cyanidin was generated. Moreover, as can be seen in Figure $8 b$, another fragmented ion molecule $(m / z 582.4)$ was detected and its molecular weight corresponded exactly with $[\mathrm{M}-\text { rhamnose }]^{+}$. The $\beta-(1,6)$ linkage between glucose and rhamnose residues may be weaker than other glycosidic bonds in Cya-3-O-xylrut, which thus resulted inCya-3-O-rut during fragmentation. According to a few studies, $\mathrm{Cya}-3-\mathrm{O}$-xylrut was one of the major anthocyanins in red currant [25], and the structure of Cya-3-O-xylrut is shown in Figure 8e [26]. Thus, $S$. chinensis may be a unique source of highly pure Cya-3-O-xylrut.

\subsection{Antioxidant Activities of Anthocyanins}

\subsubsection{Determination of Total Phenolic Content}

The radical scavenging ability and antioxidant activities of phenolic compounds are because of their hydroxyl groups [27]. As shown in Table 3, the total phenolic content of anthocyanins before purification with HPD-300 was 116.55 (mg/g catechins equivalents). The total phenolic content of anthocyanins after purification with HPD-300 was 519.55 (mg/g catechins equivalents). In short, the total phenolic content of $S$. chinensis anthocyanins consisting exclusively of Cya-3-Oxylrut increased 4.5-fold.
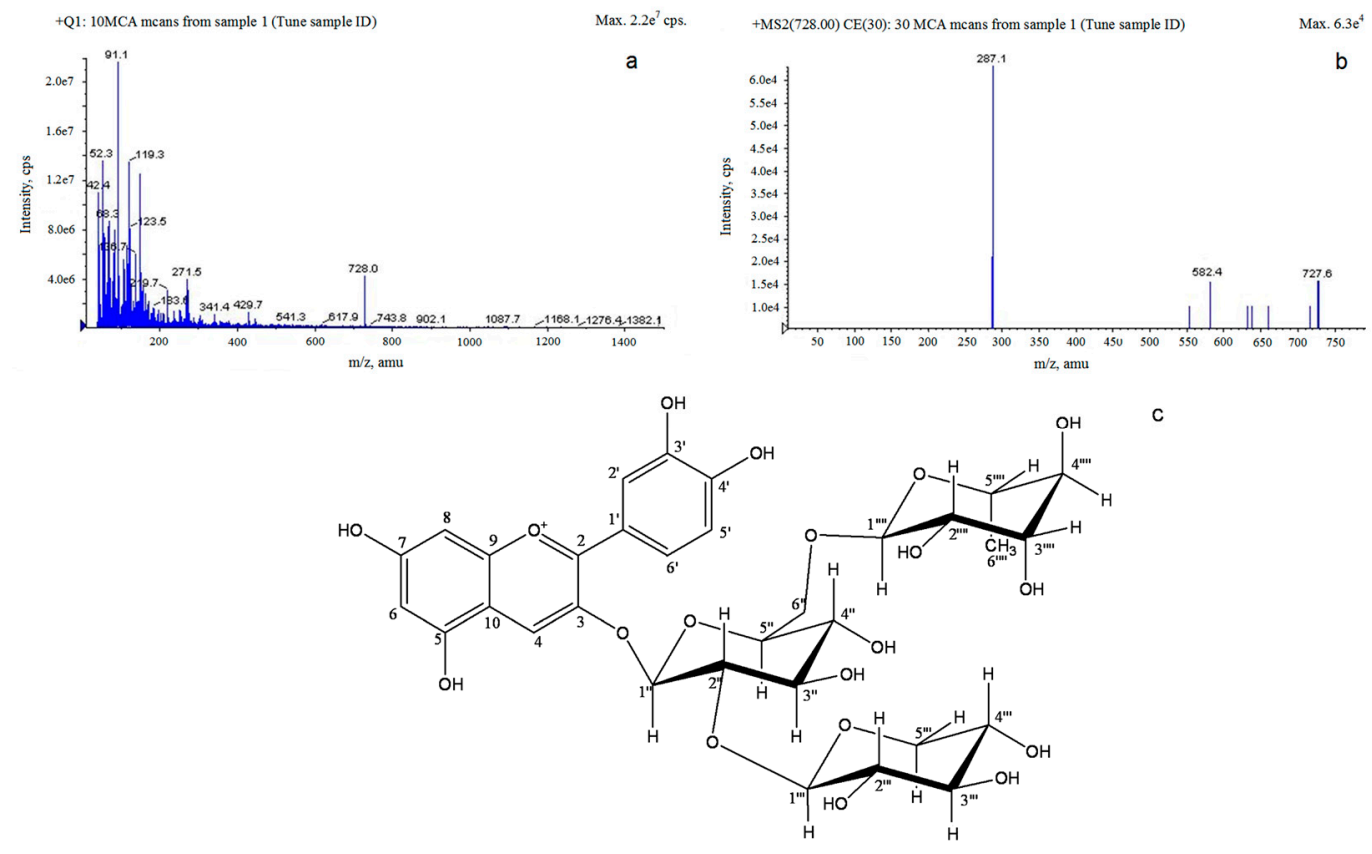

Figure 8. LC-MS chromatograms of Cyanidin-3-O-xylosylrutinoside: (a) MS1 chromatograms of cyanidin-3-O-xylosylrutinoside under ESI-MS in positive mode; (b) MS2 chromatograms of cyanidin-3-O-xylosylrutinoside under ESI-MS in positive mode; and (c) Proposed structure of cyanidin-3-O-xylosylrutinoside as an anthocyanin in S. chinensis. 


\subsubsection{Ferric Reducing Antioxidant Power (FRAP)}

The reduction capacity of a compound may serve as a significant indicator of its potential antioxidant activity [28]. A higher absorbance indicated a higher ferric reducing power. As displayed in Table 3, the reducing power of the sample before purification with HPD-300 was 754.05 (g Trolox equivalents) and 902.05 (g Trolox equivalents) after purification with HPD-300. In brief, the reducing power of S. chinensis anthocyan consisting exclusively of Cya-3-Oxylrut increased 1.2-fold.

\subsubsection{Free Radical Scavenging Activity (ABTS)}

From Table 3, the contribution of anthocyanins on the extract's total ABTS radical scavenging activities was determined to be 368.727 (g Trolox equivalents) before purification with HPD-300, and 631.455 (g Trolox equivalents) after purification with HPD-300. Therefore, our results suggest that S. chinensis anthocyanins consisting exclusively of Cya-3-Oxylrut increased 1.7-fold.

Table 3. Results of antioxidant activity tests.

\begin{tabular}{ccc}
\hline Tests & $\begin{array}{c}\text { Before purification } \\
\text { with HPD-300 }\end{array}$ & $\begin{array}{c}\text { After Purification } \\
\text { with HPD-300 }\end{array}$ \\
\hline Concentration of anthocyanin $(\mathrm{mg} / \mathrm{mL})$ & 0.474 & 1.247 \\
Purity of anthocyanin $(\%)$ & 5.08 & 30.43 \\
Total phenolic content of anthocyanins $(\mathrm{mg} / \mathrm{g}$ catechins equivalents) & 116.55 & 519.55 \\
Ferric reducing antioxidant power of anthocyanins (TE/g) & 754.050 & 902.050 \\
Free radical scavenging activity of anthocyanins (TE/g) & 368.727 & 631.455 \\
\hline
\end{tabular}

\section{Experimental Section}

\subsection{Materials}

S. chinensis fruit was purchased from San Keshu Trading (Heilongiiang, China) and identified by Prof. Shao-quan Nie from the Key Laboratory of Forest Plant Ecology, Northeast Forestry University. The same batch of sample was used in these experiments.

Folin-Ciocalteu's reagent, 2,2'-azinobis-(3-ethylbenzothiazoline-6-sulfonic acid) (ABTS, 95\%), and 6-hydroxy-2,5,7,8-tetramethylchromane-2-carboxylic acid (Trolox) were purchased from Sigma-Aldrich (St. Louis, MO, USA).

All the reagents obtained from Beijing Chemical Reagents Co. (Beijing, China) were of analytical grade. Deionized water was purified by a Milli-Q water purification system from Millipore (Bedford, MA, USA). Acetonitrile and acetic acid of HPLC grade were purchased from J \& K Chemical Ltd. (Beijing, China), and macroporous resins were purchased from Guangfu Fine Chemical Research Institute (Tianjin, China).

\subsection{Methods}

\subsubsection{Preparation of S. chinensis Anthocyanins Extracts}

S. chinensis fruits (150.0 g) were sieved using a 40-60 mesh after crushing, and then extracted with stirring using $1500 \mathrm{~mL} \mathrm{1.0} \mathrm{M} \mathrm{hydrochloric} \mathrm{acid} \mathrm{[14].} \mathrm{The} \mathrm{supernatant} \mathrm{fluid} \mathrm{after} \mathrm{filtration} \mathrm{was}$ extracted two times with the same volume of petroleum ether, then the fat-soluble impurities were removed, and extracted two times with the same volume of ethyl acetate, and then the water layer was used for future purification and antioxidant experiments.

\subsubsection{Static Adsorption and Desorption Tests}

One gram of macroporous resin (dry weight) with $50 \mathrm{~mL}$ of the anthocyanins solution, which was extracted as described in Section 3.2.1, was shaken in a table concentrator at $100 \mathrm{rpm}$ for $8 \mathrm{~h}$ at $25^{\circ} \mathrm{C}$. After adsorption, the resin was washed with $50 \mathrm{~mL}$ of deionized water, and then static desorption was 
performed with $50 \mathrm{~mL}$ of ethanol solution by shaking at $25^{\circ} \mathrm{C}$ for $8 \mathrm{~h}$. The process was repeated three times for each set of conditions. Adsorption temperature curves on the HPD-300 resin were tested at $0,10,20,30$ and $40^{\circ} \mathrm{C}$, respectively. Adsorption isotherms on the HPD-300 resin were tested with sample concentrations of $4 C_{0}, 2 C_{0}, C_{0}, 0.5 C_{0}$, and $0.25 C_{0}\left(C_{0}=0.474 \mathrm{mg} / \mathrm{mL}\right.$, which was the initial concentration of anthocyanins in the sample solution).

\subsubsection{Dynamic Adsorption and Desorption Tests}

Dynamic adsorption and desorption experiments were carried out using a fixed-bed column separator $(15 \mathrm{~mm} \times 300 \mathrm{~mm})$ wet-packed with $5.0 \mathrm{~g}$ of dry HPD-300 resin. The height of the resin bed was about $12.5 \mathrm{~cm}$ and the bed volumes (BV) of resin were approximately $13 \mathrm{~mL}$. The crude extract solution was pumped through the fixed-bed at $39 \mathrm{~mL} / \mathrm{h}$, which was $3 \mathrm{BV} / \mathrm{h}$ for HPD-300. When the adsorption reached equilibrium, the fixed-bed column separator was washed with $39 \mathrm{~mL}$ of distilled water (3 BV), and then $32 \mathrm{~mL}(2.5 \mathrm{BV})$ of ethanol-water $(90: 10, v / v)$ at room temperature was injected into the fixed-bed column separator at $13 \mathrm{~mL} / \mathrm{h}(1 \mathrm{BV} / \mathrm{h})$ by a metering pump.

\subsubsection{Regeneration of Resins}

First, the exhausted macroporous resins were soaked with $95 \%$ ethanol solution (1.0 g dry resin: $25 \mathrm{~mL} \mathrm{95 \%} \mathrm{ethanol} \mathrm{solution),} \mathrm{and} \mathrm{then} \mathrm{washed} \mathrm{successively} \mathrm{with} 1 \mathrm{~mol} / \mathrm{L} \mathrm{NaOH}(10 \mathrm{BV})$ and $1 \mathrm{~mol} / \mathrm{L}$ $\mathrm{HCl}(10 \mathrm{BV})$. Finally, the resins were washed with deionized water until the $\mathrm{pH}$ was about 7.

\subsubsection{Gel Filtration Chromatography}

About $400 \mathrm{~mL}$ of anthocyanins solution, obtained by a scale-up experiment on the macroporous resin, were subjected to molecular exclusion chromatography. A glass column with a $15 \mathrm{~mm}$ ID and $300 \mathrm{~mm}$ length was packed with Bio-Gel P2andequilibrated with one and a half column volumes of acetic acid. The sample was then eluted with acetic acid, $\mathrm{pH} 2.5$ at flow rate of $0.8 \mathrm{~mL} / \mathrm{min}$, and elution sample volumes ( $4 \mathrm{~mL} /$ tube) were collected using a fraction collector and were monitored by a spectrophotometer at $520 \mathrm{~nm}$ (Shimadzu 160 spectrophotometer). The column was then washed with acetic acid, $\mathrm{pH} 2.5$ until no further anthocyanins were eluted. Anthocyanin-rich fractions were identified and concentrated under vacuum prior to further identification.

\subsubsection{LC-ESI-MS Analysis Method}

An Agilent 1100 series HPLC system equipped with a G1312A Bin pump and G1379A Degasser (Agilent, San Jose, CA, USA), and a G1316A automatic column temperature control box and 2487 UV-detector (Waters, Boston, MA, USA) was used. Chromatographic separation was performed on a HiQ sil-C18 reversed-phase column $(4.6 \mathrm{~mm} \times 250 \mathrm{~mm}, 5 \mu \mathrm{m}$, KYA Technologies Corporation, Tokyo, Japan). Three percent acetic acid solution was used as eluent A, and HPLC-grade acetonitrile was used as eluent B. The gradient profile began at $10 \%-15 \%$ B at $40 \mathrm{~min}, 20 \%$ B at $45 \mathrm{~min}$, and subsequently at an isocratic flow with $20 \% \mathrm{~B}$ for $20 \mathrm{~min}$, and then returned to initial conditions at $65 \mathrm{~min}$ and kept for $5 \mathrm{~min}$. The flow rate was $1.0 \mathrm{~mL} / \mathrm{min}$, and the column temperature was maintained at $25^{\circ} \mathrm{C}$. The injection volume was $10 \mu \mathrm{L}$, and the detection wavelength was $520 \mathrm{~nm}$.

An API3000 Triple tandem quadrupole mass spectrometer with a Turbolon-Spray interface from Applied Biosystems (Applied Biosystems, Foster City, CA, USA) was operated in positive electro spray ionization (ESI+, $m / z$ 100-1000) source mode. All mass spectra were acquired in multiple reaction monitoring transitions. Detection was achieved by monitoring transitions of $728.0>287.1$ for Cya-3-O-xylrut in ESI+ mode. The analytical conditions were as follows: the ion source was operated at a temperature of $250{ }^{\circ} \mathrm{C}$. The nebulizing gas and nebulizer pressure was $380 \mathrm{~Pa}$. The ion spray voltage was $4500 \mathrm{~V}$. The entrance and focusing potentials were set at 10 and $375 \mathrm{~V}$. The declusterings potential was 80. Analyst software (version 1.4) [29] installed on a Dell computer was used for data acquisition and processing. 


\subsubsection{Antioxidant Activities Test Methods}

\section{Folin-Ciocalteu Assay}

The total phenolic content of anthocyanins was estimated by a colorimetric assay based on a published procedure [30], with slight modifications. Sample $(1 \mathrm{~mL})$ was pipetted into a tube; $1 \mathrm{~mL}$ of $50 \%$ Folin-Ciocalteu's reagent and $1 \mathrm{~mL}$ of $10 \%$ sodium carbonate solution were added. The contents were vortexed for $30 \mathrm{~s}$ and allowed to stand at room temperature for $2 \mathrm{~h}$. Absorbance measurements were recorded at $765 \mathrm{~nm}$, using catechins to construct the curves. The results were reported as mean values expressed as $\mathrm{mg}$ of catechins equivalents per gram of sample.

\section{Ferric Reducing Antioxidant Power (FRAP)}

The reducing antioxidant capacity was determined using a modification of the FRAP assay [31]. The FRAP reagent was prepared from $300 \mathrm{mM}, \mathrm{pH}$ 3.6, acetate buffer, $20 \mathrm{mM}$ ferric chloride and $10 \mathrm{mM}$ 2,4,6-tripyridyl-S-triazine made up in $40 \mathrm{mM}$ hydrochloric acid. All three solutions were mixed together in the ratio of 25:2.5:2.5 $(v / v / v)$. The FRAP assay was performed using reagents preheated to $38{ }^{\circ} \mathrm{C}$. Prior to analysis, the initial absorbance of $3 \mathrm{~mL}$ of the reagents, and a $3 \mathrm{~mL}$ acetate buffer used as blank, were measured at $593 \mathrm{~nm}$. The samples $(100 \mu \mathrm{L})$ were transferred into the test tubes containing the reagent. The mixtures were shaken thoroughly and examined after $90 \mathrm{~min}$ using the spectrophotometer. The absorbance values at $593 \mathrm{~nm}$ were recorded. A higher absorbance indicated a higher ferric reducing power, and the tests were carried out in triplicate. The reducing antioxidant power of the sample was expressed as Trolox equivalent, which was the ratio between the slope of the sample's regression line and that of Trolox.

\section{Free Radical Scavenging Activity (ABTS)}

The method of Wojdylo et al. [32] was used with slight modification. 2,2'-Azinobis(3-ethylbenzthiazoline-6-sulphonate) (ABTS) diammonium salt $(7 \mathrm{mM})$ and potassium persulfate $(2.45 \mathrm{mM})$ were mixed and kept in the dark at room temperature for $18 \mathrm{~h}$ before use. For this study, the ABTS radical solution was diluted with methanol to an absorbance of $0.7 \mathrm{at} 734 \mathrm{~nm}$. The sample solution $(0.05 \mathrm{~mL})$ was added to $1 \mathrm{~mL}$ of the blue-green ABTS radical solution. The mixture was shaken vigorously and allowed to reach a steady state at room temperature in a dark for $1 \mathrm{~min}$. The decrease in absorbance was measured at $734 \mathrm{~nm}$, and the control consisted of $0.05 \mathrm{~mL}$ of Trolox-methanol solution and $1 \mathrm{~mL}$ of ABTS radical solution. The tests were carried out in triplicate and the free radical scavenging activity of the sample was expressed as Trolox equivalent.

\subsubsection{Statistical Analysis}

Statistical analysis of the data was performed by analysis of variance (ANOVA), and the significance of the difference between means was determined by Duncan's multiple range test $(p<0.05)$ using SAS (Version 8.1, 2000; SAS Inst., Cary, NC, USA). Values are expressed as "mean \pm standard deviation".

\subsubsection{Calculation Methods}

Total Monomeric Anthocyanins (TMA)

Total anthocyanins content was measured using the $\mathrm{pH}$ differential method [14], which became a standard AOAC analysis method in 2005, with minor modifications using a UV-2550 UV-Vis spectrophotometer (Shimadzu, Japan). The crude anthocyanins extracts were dissolved in potassium chloride buffer $(\mathrm{KCl}, 0.025 \mathrm{M}, \mathrm{pH} 1.0)$ and sodium acetate $\left(\mathrm{CH}=\mathrm{COONa} \bullet 3 \mathrm{H}_{2} \mathrm{O}, 0.4 \mathrm{M}, \mathrm{pH} 4.5\right)$ with a pre-determined dilution factor. The absorbance of the measured samples was read at $510 \mathrm{~nm}$ and $700 \mathrm{~nm}$ against a blank cell containing deionized water. Results were expressed as $\mathrm{mg} / \mathrm{mL}$ 
of equivalent cyanidin-3-glucoside. The absorbance (A) of the diluted sample was then calculated as follows:

$$
\mathrm{A}=\left(\mathrm{A}_{510 \mathrm{~nm}}-\mathrm{A}_{700 \mathrm{~nm}}\right) \mathrm{pH} 1.0-\left(\mathrm{A}_{510 \mathrm{~nm}}-\mathrm{A}_{700 \mathrm{~nm}}\right) \mathrm{pH} 4.5
$$

The monomeric anthocyanins pigment concentration in the original sample was calculated according to the following formula:

$$
\text { Anthocyanins content }(\mathrm{mg} / \mathrm{mL})=\mathrm{A} \times \mathrm{MW} \times \mathrm{DF} \times 1000 /(\varepsilon \times 1)
$$

where the molecular weight of cyanidin-3-glucoside ( $\mathrm{MW}=449.2)$, the dilution factor or dilution multiple ( $\mathrm{DF}=5)$ and a molar extinction coefficient of cyanidin-3-glucoside of $29,600(\varepsilon=29,600)[33,34]$ were used.

\section{Adsorption and Desorption Evaluation}

The adsorption was evaluated using the following equation:

$$
\begin{gathered}
Q_{e}=\left(C_{0}-C_{e}\right) \times V_{i} \times(1-M) \times W \\
D_{e}(\%)=Q_{e} /\left(C_{0} \times V_{i}\right) \times 100 \%
\end{gathered}
$$

where $Q_{e}$ was the adsorption capacity at adsorption equilibrium $\left(\mu \mathrm{g} / \mathrm{g}\right.$ anhydrous resin); $C_{0}$ and $C_{e}$ were the initial and equilibrium concentrations of anthocyanins, respectively $(\mu \mathrm{g} / \mathrm{mL}) ; V_{i}$ was the volume of the initial sample solution $(\mathrm{mL}) ; M$ was moisture content; and $W$ was the mass of resin $(\mathrm{g})$; $D_{e}$ was the adsorption ratio (\%).

Desorption was evaluated using the following equations:

$$
\begin{gathered}
Q_{d}=C_{d} \times V_{d}(1-M) \times W \\
D_{d}(\%)=Q_{d} / Q_{e} \times 100 \%=C_{d} \times V_{d} \times\left(C_{0}-C_{e}\right) \times V_{i} \times 100 \%
\end{gathered}
$$

where $Q_{d}$ was the desorption capacity after adsorption equilibrium ( $\mu \mathrm{g} / \mathrm{g}$ anhydrous resin); $C_{d}$ was the concentration of anthocyanins in the desorption solution $(\mu \mathrm{g} / \mathrm{mL}) ; V_{d}$ was the volume of the desorption solution (mL); $D_{d}$ was the desorption ratio (\%); and $C_{0}, C_{e}, V_{i}$ and $M$ were as described above.

Adsorption Isotherms

The Langmuir adsorption model can be expressed by the following equation:

$$
Q_{e}=Q_{m} \times C_{e} /\left(K+C_{e}\right)
$$

where $Q_{e}(\mu \mathrm{g} / \mathrm{g})$ was the concentration of solute per mass of adsorbent (solid phase), also known as the adsorptive capacity; $C_{e}(\mu \mathrm{g} / \mathrm{mL})$ was the concentration of solute in solution (liquid phase) at equilibrium; K was the Langmuir constant; and $Q_{m}$ was an empirical constant.

The Freundlich equation can be expressed as follows:

$$
Q_{e}=K C_{e}^{1 / n}
$$

Alternatively, in the form:

$$
\ln Q_{e}=\ln K+1 / n \times \ln C_{e}
$$

where $K$ was the Freundlich constant, which was an indicator of adsorption capacity; and $1 / n$ was an empirical constant related to the magnitude of the adsorption driving force. 
Purity Evaluation

The purity was evaluated using the following equation:

$$
P=M_{A} / M_{T} \times 100 \%
$$

where $P$ was the purity of anthocyanins (\%); $M_{A}$ was the mass of anthocyanins in the dry products (mg); and $M_{T}$ was the total mass of dry products (mg).

\section{Conclusions}

In present study, the parameters of a S. chinensis anthocyanins purification process by macroporous resin and gelfiltration chromatography were evaluated. The purity of anthocyanins after purification by HPD-300 increased six-fold from $5.08 \%$ to $30.43 \%$, and the anthocyanins recovery was $96.5 \%$. The gel-filtration resin used was Bio-Gel P2, and the recycle yield of anthocyanins was $89.24 \%$. The results reflected the advantages of the adsorption-desorption method, which are lower cost, high efficiency, procedural simplicity, and environmental friendliness. The combined method of macroporous resin plus gel filtration chromatography is valuable and practical strategy for separating the high-purity anthocyanins from other herbal plants. The major constituent of $S$. chinensis anthocyanins was cyanidin-3-O-xylosylrutinoside as determined by LC-MS. Moreover, the antioxidant activities of S. chinensis anthocyanins were investigated. After purification by HPD-300 resin, the total phenolic content of anthocyanins was increased 4.5-fold, while the antioxidant activities of anthocyanins were also increased 1.2-fold (FRAP) and 1.7-fold (ABTS). The results of antioxidant activities study show that $S$. chinensis anthocyanins with notable antioxidant properties for potential use in nutraceutical or functional food formulations as preservatives and colorants.

Acknowledgments: The authors acknowledge the financial support from the Special Fund for Forest Scientific Research in the Public Welfare (No. 201504605), the National Natural Science Foundation of China (No. 31500467, 31570567), Natural Science Foundation of Heilongjiang Province for Young Scholar (QC2015034), Zhejiang Key Level 1 Discipline of Forestry Engineering (No. 2014lygcz017) and the Research start-up funding of introducing talents at the Northeast Forestry University.

Author Contributions: Conceived and designed the experiments: Chunhui Ma, Lei Yang, and Wei Li; performed the experiments: Daran Yue and Chunhui Ma; analyzed the data: Daran Yue and Chunhui Ma; contributed reagents/materials/analysis tools: Shouxin Liu and Jian Li; and contributed to the writing of the manuscript: Chunhui Ma and Wei Li.

Conflicts of Interest: The authors declare no conflict of interest.

\section{References}

1. Garzón, G.A.; Wrolstad, R.E. Major anthocyanins and antioxidant activity of Nasturtium flowers (Tropaeolum majus). Food Chem. 2009, 114, 44-49. [CrossRef]

2. Kerio, L.C.; Wachira, F.N.; Wanyoko, J.K.; Rotich, M.K. Characterization of anthocyanins in Kenyan teas: Extraction and identification. Food Chem. 2012, 131, 31-38. [CrossRef]

3. Lule, S.U.; Xia, W. Food phenolics, pros and cons: A review. Food Rev. Int. 2005, 21, 367-388. [CrossRef]

4. Nichenametla, S.N.; Taruscio, T.G.; Barney, D.L.; Exon, J.H. A review of the effects and mechanisms of polyphenolics in cancer. Crit. Rev. Food Sci. 2006, 46, 161-183. [CrossRef] [PubMed]

5. Lohachoompol, V.; Mulholland, M.; Srzednicki, G.; Craske, J. Determination of anthocyanins in various cultivars of highbush and rabbiteye blueberries. Food Chem. 2008, 111, 249-254. [CrossRef]

6. Kong, J.M.; Chia, L.S.; Goh, N.K.; Chia, T.F.; Brouillard, R. Analysis and biological activities of anthocyanins. Phytochemistry 2003, 64, 923-933. [CrossRef]

7. Özgen, M.; Serçe, S.; Kaya, C. Phytochemical and antioxidant properties of anthocyanin-rich Morus nigra and Morus rubra fruits. Sci. Hortic. 2009, 119, 275-279. [CrossRef]

8. Hancke, J.L.; Burgos, R.A.; Ahumada, F. Schisandra chinensis (Turcz.) Baill. Fitoterapia 1999, 70, 451-471. [CrossRef] 
9. Li, X.N.; Cui, H.; Song, Y.Q.; Liang, Y.Z.; Chau, F.T. Analysis of volatile fractions of Schisandra chinensis (Turcz.) Baill. using GC-MS and chemometric resolution. Phytochem. Anal. 2003, 14, 23-33. [CrossRef] [PubMed]

10. Ma, C.H.; Liu, T.T.; Yang, L.; Zu, Y.G.; Chen, X.Q.; Zhang, L.; Zhang, Y.; Zhao, C.J. Ionic liquid-based microwave-assisted extraction of essential oil and biphenyl cyclooctene lignans from Schisandra chinensis Baill fruits. J. Chromatogr. A 2011, 1218, 8573-8580. [CrossRef] [PubMed]

11. Choi, Y.W.; Takamatsu, S.; Khan, S.I.; Srinivas, P.V.; Ferreira, D.; Zhao, J.; Khan, I.A. Schisandrene, a dibenzocyclooctadiene lignan from Schisandra chinensis: Structure-antioxidant activity relationships of dibenzocyclooctadiene lignans. J. Nat. Prod. 2006, 69, 356-359. [CrossRef] [PubMed]

12. Ma, C.H.; Liu, T.T.; Yang, L.; Zu, Y.G.; Yang, F.J.; Zhao, C.J.; Zhang, L.; Zhang, Z.H. Preparation of high purity biphenyl cyclooctene lignans from Schisandra extract by ion exchange resin catalytic transformation combined with macroporous resin separation. J. Chromatogr. B 2011, 879, 3444-3451. [CrossRef] [PubMed]

13. Ma, C.H.; Liu, T.T.; Yang, L.; Zu, Y.G.; Wang, S.Y.; Zhang, R.R. Study on ionic liquid-based ultrasonic-assisted extraction of biphenyl cyclooctene lignans from the fruit of Schisandra chinensis Baill. Anal. Chim. Acta 2011, 689, 110-116. [CrossRef] [PubMed]

14. Ma, C.H.; Yang, L.; Yang, F.J.; Wang, W.J.; Zhao, C.J.; Zu, Y.G. Content and colour stability of anthocyanins isolated from Schisandra chinensis (Turcz.) Baill fruits. Int. J. Mol. Sci. 2012, 13, 14294-14310. [CrossRef] [PubMed]

15. Bordonaba, J.G.; Crespo, P.; Terry, L.A. A new acetonitrile-free mobile phase for HPLC-DAD determination of individual anthocyanins in blackcurrant and strawberry fruits: A comparison and validation study. Food Chem. 2011, 129, 1265-1273. [CrossRef] [PubMed]

16. Khanal, R.C.; Howard, L.R.; Prior, R.L. Effect of heating on the stability of grape and blueberry pomace procyanidins and total anthocyanins. Food Res. Int. 2010, 43, 1464-1469. [CrossRef]

17. Elisia, I.; Hu, C.; Popovich, D.G.; Kitts, D.D. Antioxidant assessment of an anthocyanin-enriched blackberry extract. Food Chem. 2007, 101, 1052-1058. [CrossRef]

18. Kırca, A.; Özkan, M.; Cemeroğlu, B. Effects of temperature, solid content and pH on the stability of black carrot anthocyanins. Food Chem. 2007, 101, 212-218. [CrossRef]

19. Zou, T.B.; Wang, M.; Gan, R.Y.; Ling, W.H. Optimization of ultrasound-assisted extraction of anthocyanins from mulberry, using response surface methodology. Int. J. Mol. Sci. 2011, 12, 3006-3017. [CrossRef] [PubMed]

20. Liang, Z.C.; Wu, B.H.; Fan, P.G.; Yang, C.X.; Duan, W.; Zheng, X.B.; Liu, C.Y.; Li, S.H. Anthocyanin composition and content in grape berry skin in Vitis germplasm. Food Chem. 2008, 111, 837-844. [CrossRef]

21. Fan, G.J.; Han, Y.B.; Gu, Z.X.; Gu, F.R. Composition and colour stability of anthocyanins extracted from fermented purple sweet potato culture. LWT-Food Sci. Technol. 2008, 41, 1412-1416. [CrossRef]

22. Chen, F.; Sun, Y.Z.; Zhao, G.H.; Liao, X.J.; Hu, X.S.; Wu, J.H.; Wang, Z.F. Optimization of ultrasound-assisted extraction of anthocyanins in red raspberries and identification of anthocyanins in extract using high-performance liquid chromatography-mass spectrometry. Ultrason. Sonochem. 2007, 14, 767-778. [CrossRef] [PubMed]

23. Jia, G.T.; Lu, X.Y. Enrichment and purification of madecassoside and asiaticoside from Centella asiatica extracts with macroporous resins. J. Chromatogr. A 2008, 1193, 136-141. [CrossRef] [PubMed]

24. Kim, S.H.; Lee, B.H.; Kim, J.C.; Choi, S.S.; Kim, G.W.; Joo, M.H.; Yoo, S.H. Compositional characterization and colorant identification of Omija (Schizandra chinensis) fruit extract. Food Sci. Biotechnol. 2008, 17, 787-793.

25. Goiffon, J.P.; Mouly, P.P.; Gaydou, E.M. Anthocyanin pigment determination in red fruit juices, concentrated juices and syrups using liquid chromatography. Anal. Chim. Acta 1999, 382, 39-50. [CrossRef]

26. Kim, S.H.; Joo, M.H.; Yoo, S.H. Structural identification and antioxidant properties of major anthocyanin extracted from Omija (Schizandra chinensis) fruit. J. Food Sci. 2009, 74, 134-140. [CrossRef] [PubMed]

27. Hatano, T.; Edamatsu, R.; Hiramatsu, M.; Mori, A.; Fujita, Y.; Yasuhara, T.; Yoshida, T.; Okuda, T. Effect of interaction of tannins with co-existing substances VI. Effect of tannins and related polyphenols on superoxide anion radical and on DPPH radical. Chem. Pharm. Bull. 1989, 37, 2016-2021. [CrossRef]

28. Meir, S.; Kanner, J.; Akiri, B.; Hadas, S.P. Determination and involvement of aqueous reducing compounds in oxidative defense systems of various senescing leaves. Agric. Food Chem. 1995, 43, 1813-1815. [CrossRef] 
29. Zu, Y.; Yan, M.; Fu, Y.; Liu, W.; Zhang, L.; Gu, C.; Efferth, T. Determination and quantification of astragalosides in Radix Astragali and its medicinal products using LC-MS. J. Sep. Sci. 2009, 32, 517-525. [CrossRef] [PubMed]

30. Liu, X.; Jia, J.; Yang, L.; Yang, F.; Ge, H.; Zhao, C.; Zhang, L.; Zu, Y. Evaluation of antioxidant activities of aqueous extracts and fractionation from different parts of Elsholtzia ciliate. Molecules 2012, 17, 5430-5441. [CrossRef] [PubMed]

31. Loo, A.Y.; Jain, K.; Darah, I. Antioxidant and radical scavenging activities of the pyroligneous acid from a mangrove plant. Food Chem. 2007, 104, 300-307. [CrossRef]

32. Wojdylo, A.; Oszmia'nski, J.; Czemerys, R. Antioxidant activity and phenolic compounds in 32 selected herbs. Food Chem. 2007, 105, 940-949. [CrossRef]

33. Ehlenfeldt, K.M.; Prior, L.R. Oxygen radical absorbance capacity (ORAC) and phenolic and anthocyanin concentration in fruit and leaf tissues of highbush blueberry. J. Agric. Food Chem. 2001, 49, 2222-2227. [CrossRef] [PubMed]

34. Francis, F.G. Food colorants: Anthocyanins. Crit. Rev. Food Sci. Nutr. 1989, 28, 273-314. [CrossRef] [PubMed]

Sample Availability: Samples of S. chinensis anthocyanins are not available from the authors.

(c) 2016 by the authors; licensee MDPI, Basel, Switzerland. This article is an open access article distributed under the terms and conditions of the Creative Commons by Attribution (CC-BY) license (http:/ / creativecommons.org/licenses/by/4.0/). 